\title{
A STUDY OF ECG INTERVALS IN HEALTHY YOUNG MALE SMOKERS COMPARED TO NON-SMOKERS IN TERTIARY CARE HOSPITAL
}

\author{
Makarand Mane ${ }^{1}$, Arjun Mandade2, Shreya Menon ${ }^{3}$, Ajit Sathe ${ }^{4}$, Abhijit Patil 5
}

1Associate Professor, Department of Medicine, Krishna Institute of Medical Sciences, Karad.

${ }^{2} 3^{\text {rd }}$ Year Resident, Department of Medicine, Krishna Institute of Medical Sciences, Karad.

33rd Year Resident, Department of Paediatrics, Krishna Institute of Medical Sciences, Karad.

43rd Year Resident, Department of Medicine, Krishna Institute of Medical Sciences, Karad.

53rd Year Resident, Department of Medicine, Krishna Institute of Medical Sciences, Karad.

\section{ABSTRACT}

\section{BACKGROUND}

Tobacco consumption has many worst health outcomes. Tobacco is consumed in many forms and one such form is cigarette smoking. Its use leads to sudden coronary death, chronic obstructive pulmonary disease, cancer, peripheral vascular disease, hypertension and the list is endless. ${ }^{1}$

Aim- To evaluate ECG intervals in apparently healthy young male smokers compared to non-smokers using a 12-lead ECG record. Objective- To evaluate and compare variations in ECG waves, segments and intervals in apparently 150 healthy young male smokers and 150 non-smokers.

\section{MATERIALS AND METHODS}

Descriptive comparative study over total duration of 24 months. For convenience 150 young, apparently healthy smokers and nonsmokers in the age group of 18 - 35 yrs. were taken.

Settings and Design- Medicine OPD of Krishna Institute of Medical Sciences, Karad (Tertiary Care).

\section{RESULTS}

PR interval was significantly shortened among smokers. No statistically significant difference in QRS interval between the two groups. QTC interval was slightly higher among smokers $(0.38 \mathrm{sec})$ than non-smokers. TP interval was $0.29 \pm 0.014,0.25 \pm 0.014$ among control and smokers respectively. There is statistically significant decrease seen in smokers.

\section{CONCLUSION}

Smoking induces significant alteration in cardiac electrophysiology like shortening of PR and TP interval, prolongation of QTc interval in apparently healthy young individuals, which may predispose to cardiovascular morbidity and mortality in the long run.

\section{KEYWORDS}

ECG, Healthy Young, Smokers, Non-Smokers.

HOW TO CITE THIS ARTICLE: Mane M, Mandade A, Menon S, et al. A study of ECG intervals in healthy young male smokers compared to non-smokers in tertiary care hospital. J. Evolution Med. Dent. Sci. 2018;7(09):1162-1165, D0I: $10.14260 /$ jemds/2018/264

\section{BACKGROUND}

According to World Health Report (2002), ${ }^{2}$ tobacco is the most preventable cause of overall as well as cardiovascular mortality worldwide. It was estimated that there were 100 million deaths worldwide in the 20th century. The total number of tobacco users in the world has been estimated at 1.2 billion, which is expected to rise to 1.6 billion during year 2020 's. At present, tobacco use causes death of 3.5 to 4 million people globally and expected to increase about 10 million during year 2020.3 It has also been estimated that by 2030, there will be more than 8 million deaths every year. ${ }^{4}$

Smoking has resulted in two-fold increase in the risk of Coronary Artery Diseases. The consumption of nicotine is the single biggest avoidable cause of death and disability.

'Financial or Other Competing Interest': None.

Submission 23-11-2017, Peer Review 14-02-2018,

Acceptance 20-02-2018, Published 26-02-2018.

Corresponding Author:

Dr. Makarand Mane,

Plot No. 8,

Gajanan Housing Society,

Station Road, Karad.

E-mail: makarand.mane@gmail.com

DOI: $10.14260 /$ jemds $/ 2018 / 264$
The World Health Organisation (WHO) predicts that 70\% of the deaths from smoking-related illnesses will occur in low- and middle-income countries by 2020. Smokers are found worldwide, while tobacco chewers are restricted to South East Asia. Uttar Pradesh is the third largest cultivator of tobacco leaf in India. Tobacco is produced mainly in Mainpuri, Muradabad, Farrukhabad and Etah districts in UP. There are many cigarette and gutka factories in the state. ${ }^{5}$

Black HR et al, ${ }^{6}$ Jonas MA et al,7 Willete et al. ${ }^{8}$ MMWR, US, ${ }^{9}$ and Price JF et al ${ }^{10}$ have conducted epidemiologic studies, which strongly support the assertion that cigarette smoking (CS) in both men and women increases the incidence of myocardial infarction (MI) and fatal coronary artery disease.

Tobacco consumption has many worse health outcomes. Tobacco is consumed in many forms and one such form is cigarette smoking. Its use leads to sudden coronary death, chronic obstructive pulmonary disease, cancer, peripheral vascular disease, hypertension and the list is endless.

Nicotine also causes cardiac death by provoking ventricular arrhythmias. ${ }^{11,12}$ The cardiac effects of nicotine are attributed to the release of catecholamine, ${ }^{13}$ which are released due to the binding of nicotine to the nicotinic cholinergic gate on the cation channels in receptors (nAchRs) throughout the body. A longer retention of nicotine occurs in 
the blood and in other specific tissues such as the oesophagus, fundus, antrum, spleen, caecum, pancreas, testes, heart and the muscle via a constant exposure. ${ }^{13}$ Nicotine facilitates a conduction block and a re-entry and it increases the vulnerability to a ventricular fibrillation. ${ }^{14}$ Nicotine is a potent inhibitor of the cardiac A type potassium channels, which contributes to the changes in the electrophysiology and it also induces arrhythmias. ${ }^{15}$ It contains nicotine, which causes physical and psychological dependencies.

Hence, nicotine and other components of cigarette smoking produce profound changes in the heart which can be assessed by doing an Electrocardiography (ECG), which is the easiest and the cheapest method for assessing cardiovascular abnormalities. Maintaining abstinence from smoking as early as possible can prevent further damage. This study was aimed at creating awareness on the smoking hazards.

\section{Statistical Analysis Used}

The data was compiled in Microsoft Excel and analysed using SPSS (Statistical Package for Social Sciences) version 15. Level of significance was fixed at $p<0.05$ with student's ' $t$ ' test.

\section{Aim}

To evaluate ECG intervals in apparently healthy young male smokers compared to non-smokers using a 12-lead ECG record.

\section{Objectives}

To evaluate and compare variations in ECG waves, segments and intervals in apparently 150 healthy young male smokers and 150 non-smokers.

\section{MATERIALS AND METHODS}

Method of collection of data (including sampling procedure, if any).

\section{Type of Study}

Descriptive comparative study.

\section{Sample Size}

Total- 300.

\section{Inclusion Criteria}

Young males between the age of 18 - 35 years visiting tertiary care centre.

\section{Exclusion Criteria}

- Males diagnosed with hypertension.

- History of cardiac, respiratory, renal and endocrine disorders.

- History of consumption of psychoactive substances.

- Family history of hypertension and smoking.

- History of cardiac diseases.

- History of anxiety.

- History of depressive disorders.

- Passive smokers.

\section{Duration of Study}

Total Duration: 24 months.

\section{Study Setting}

Medicine OPD of Krishna Institute of Medical Sciences, Karad (Tertiary Care).

\section{Cases}

150 young, apparently healthy smokers in age group of 18-35 yrs.

\section{Controls}

150 young, apparently healthy non-smokers in age group of 18-35 yrs.

\section{Source of Data}

Cases were apparently healthy male smokers between ages 18-35 years, selected from among students and staff of the institute, and attendants of patients visiting outpatient departments at the hospital. Non-smoking male controls of the same age group were selected from the same pool. The nature and purpose of the study was described to the subjects and informed written consent was obtained from those willing to participate in the study.

A pre-structured proforma was given to each subject to record personal details and pertinent medical history from both cases and controls. Details of smoking habit, that is duration and quantum of smoking, were obtained from cases. For each subject in the case group, number of pack years was calculated. One pack year $=20$ cigarettes smoked per day for a duration of one year.

Physical examination included measurement of weight in kilograms, pulse rate was recorded by palpating radial artery and blood pressure recording with a mercury sphygmomanometer. Clinical examination of cardiovascular and respiratory systems was done in detail.

The subjects were asked to visit the Outpatient Department of Medicine, in the morning hours between 9 AM to 12 noon. Each subject was allowed to rest in supine posture for 15 minutes before recording was done. After the period of rest, pulse rate was recorded in beats per minute by palpating radial artery for one minute. Blood pressure was measured using mercury sphygmomanometer from the right upper arm with the subject in supine position with 3 readings at the interval of 5 mins were obtained and mean BP was taken into consideration.

Following the standard procedure, 12-lead electrocardiograms was recorded using Magic R 12-channel Electrocardiograph designed by Medline's team of biomedical engineers. The data was compiled in Microsoft Excel and analysed using SPSS (Statistical Package for Social Sciences) version 15. Level of significance was fixed at $p<0.05$ with student's ' $\mathrm{t}$ ' test.

The ECG was evaluated for different intervals like PR interval (0.120 - $0.200 \mathrm{sec})$, QRS, QT interval, QTc interval (Male- $<0.42$, Female- $<0.44 \mathrm{sec}$ ) and TP interval.

The data was compiled in Microsoft Excel and analysed using SPSS (Statistical Package for Social Sciences) version 15. Level of significance was fixed at $\mathrm{p}<0.05$. 
RESULTS

\begin{tabular}{|c|c|c|c|}
\hline Measurements & $\begin{array}{c}\text { Smokers } \\
(\mathbf{N}-150) \\
\text { Mean +/-SD }\end{array}$ & $\begin{array}{c}\text { Non-smokers } \\
\text { (N-150) } \\
\text { Mean +/-SD }\end{array}$ & $\begin{array}{c}\text { P } \\
\text { value* }\end{array}$ \\
\hline PR interval (sec) & $0.1429+/-0.003$ & $0.1550+/-0.001$ & $<0.001$ \\
\hline QRS interval (sec) & $0.089+/-0.094$ & $0.0783+/-$ & 0.0014 \\
\hline QTC interval (sec) & $0.38+/-0.016$ & $0.37+/-0.016$ & 0.007 \\
\hline TP interval(sec) & $0.25+/-0.0149$ & $0.29+/-0.0141$ & $<0.001$ \\
\hline Table 1. Comparison of PR, QRS, QTc, TP Interval between \\
\multicolumn{3}{|c}{ smokers and Non-Smokers } \\
\hline
\end{tabular}

*Student's ' $\mathrm{t}$ ' test.

PR interval was significantly shortened among smokers $(0.1426 \mathrm{sec})$ compared to non-smokers $(0.155 \mathrm{sec})(\mathrm{p}<$ 0.001 ). But there was no statistically significant difference in QRS interval between the two groups (p- 0.163).

QTC interval was slightly higher among smokers $(0.38$ sec) than non-smokers $(0.37 \mathrm{sec})$ and this was also found to be statistically significant $(\mathrm{p}<0.007)$.

TP interval was $0.29 \pm 0.014,0.25 \pm 0.014$ among control and smokers respectively. There was statistically significant decrease seen in smokers compared with controls ( $p<$ 0.001).

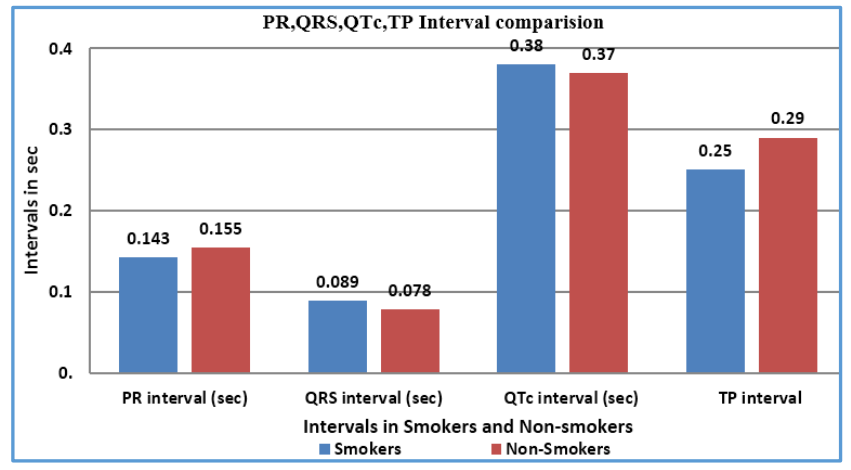

Graph 1. Comparison of PR, QRS, QTC, TP Intervals between Smokers and Non-Smokers

\section{DISCUSSION}

\section{PR Interval}

In this study, PR interval (mean) was shortened among smokers compared to non-smokers. This resultant finding was in agreement with Prashantbabu et al and other studies, ${ }^{16,17}$ but PR interval was more in smokers than nonsmokers in study done by Salman S Siddiqui et al, Swati K et al, Amit Shrivastav et al and Venkatesh G et al.18,19

Cigarette smoking increases the velocity of conduction and shortens the effective refractory period at the AV node. ${ }^{20}$ This could predispose to greater incidence of cardiac rhythm disorders in smokers. ${ }^{21}$

\section{QRS Interval}

There was no statistically significant difference between Smokers and Non-Smokers in our study. Other studies have demonstrated short QRS interval done by Salman S Siddiqui et al, Amit Shrivastav et al, Swati K et al but Venkatesh G et al and MR Renukadevi et al have observed that QRS interval was more in cases than contols. ${ }^{18,19,22}$

\section{QTc Interval}

In our study, $\mathrm{QT}_{\mathrm{C}}$ interval was slightly higher among smokers as compared to non-smokers. Similar finding was reported by Prashanthbabu et al, Venkatesh G et al, Amit Shrivastav et al and Arvind Thangarasa et al,22,23,24 but it was found that QTc was shorter in cases than controls by MR Renukadevi et al.

The Ventricular repolarisation is altered in young male cigarette smokers. The differences in the heterogeneity of ventricular repolarisation between smokers and nonsmokers are mainly due to heart rate differences between the 2 study groups. ${ }^{25}$

\section{TP Interval}

In ECG strip if heart rate would increase in distance between T-wave (end of one cardiac cycle) and P-wave starting of new cardiac cycle would decrease and is the cause of shortening of TP interval, which was found similar in study done by Salman $\mathrm{S}$ Siddiqui et al, Amit Shrivastav et al and Venkatesh G et al. 24,25

\section{CONCLUSION}

Smoking induces significant alteration in cardiac electrophysiology like shortening of PR and TP interval, prolongation of QTc interval in apparently healthy young individuals which may predispose to cardiovascular morbidity and mortality in the long run.

\section{REFERENCES}

[1] Ockene IS, Miller NH. Cigarette smoking, CVS disease and stroke: a statement for healthcare professionals from the American Heart Association. American Heart Association Task Force on Risk Reduction. Circulation 1997;96(9):3243-7.

[2] World Health Report. Reducing risks, promoting healthy life. World Health Organization, Genva: 2002: p. 47-98.

[3] WHO: Report on the Global Tobacco Epidemic. 2008.

[4] Chaudhry K. Tobacco control in India. 50 years of cancer control in India. WHO, India report 2006. URL: http://www.whoindia.org/LinkFiles/Cancer_resource _pg204to219.pdf

[5] Sinha DN. GYTS Report-Uttar Pradesh 2002. www.searo.who.int/ GYTS_Rep_UttarPradesh_2002 Agriculture, centre for monitoring Indian economy, 1999: p. 396.

[6] Black HR, Laragh JH, Brenner BM. Smoking and cardiovascular diseases. Hypertension: pathophysiology, diagnosis and management. $2^{\text {nd }}$ edn. New York, NY: Raven Press Ltd., 1995: p. 2621-47.

[7] Jonas MA, Oates JA, Ockene JK, et al. Statement on smoking and cardiovascular disease for health care professionals. American Heart Association. Circulation 1992;86(5):1664-9.

[8] Willett WC, Green A, Stampfer MJ, et al. Relative and absolute excess risks of coronary heart disease among women who smoke cigarettes. $\mathrm{N}$ Engl J Med 1987;317(21):1303-9.

[9] Centers for Disease Control and Prevention (CDC). Annual smoking attributable mortality, years of potential life lost and economic costs-United States, 1995-1999. MMWR Morb Mortal Wkly Rep 2002;51(14):300-3. 
[10] Price JF, Mowbray PI, Lee AJ, et al. Relationship between smoking and cardiovascular risk factors in the development of peripheral arterial disease and coronary artery disease: Edinburgh Artery study. Eur Heart J 1999;20(5):344-53.

[11] Chevalier HJ, Kuhnigk C, Bandilla B, et al. Effect of high doses of nicotine in pig. I. Changes of the electrocardiogram. Basic Res Cardiol 1976;71(1):6875.

[12] Escobedo LG, Zack MM. Comparison of sudden and non-sudden coronary deaths in the United States. Circulation 1996;93(11):2033-6.

[13] Chowdhury P, Doi R, Chang LW, et al. Tissue distribution of $[3 \mathrm{H}]-$ nicotine in rats. Biomed Environ Sci 1993;6(1):59-64.

[14] Yashima M, Ohara T, Cao JM, et al. Nicotine increases ventricular vulnerability to fibrillation in hearts with healed myocardial infarction. Am J Physiol Heart Circ Physiol 2000;278(6):H2124-33.

[15] Wang H, Shi H, Zhang L, et al. Nicotine is a potent Blocker of the cardiac A-type $\mathrm{K}(+)$ channels. Effects on cloned Kv4.3 channels and native transient outward current. Circulation 2000;102(10):1165-71.

[16] Baden L, Weiss ST, Thomas HE, et al. Smoking status and the electrocardiogram: a crosssectional and longitudinal study. Arch Environ Health 1982;37(6):365-9.
[17] Khan IS, Rahman MA, Amin R. Study of ECG changes in apparently healthy adult male smokers. Dinajpur Med Col J 2011;4(1):7-14.

[18] National journal of medical research. 2013;3(1):1-103.

[19] Swathi K, Garimella S. Study of ECG effects in smokers and normal. J Pharm Sci Res 2015;7(3):163-5.

[20] Venkatesh G, Swamy RM. A Study of Electrocardiographic changes in smokers compared to normal human beings. Biomedical Research 2010;21(4):389-92.

[21] Benjamin EJ, Levy D, Vaziri SM, et al. Independent risk factors for atrial fibrillation in a population-based cohort. The Framingham Heart Study. JAMA 1994;271(11):840-4.

[22] Qtc changes in smokers and non-smokers - a comparative $\quad$ study. 2012;2(3):26-7. www.iosrjournals.org

[23] Dilaveris P, Pantazis A, Gialafos E, et al. The effects of cigarette smoking on the heterogeneity of ventricular repolarization. AM Heart J 2001;142(5):833-7.

[24] Mallikarjuna V, Prashanthbabu G, Arunkumar S, et al. A study of ECG changes in healthy young smokers compared to non-smokers. IJBMS 2017;7(5).

[25] Srivastava A, Poonia A, Shekhar S. A comparative electrocardiographic changes between non-smokers and smokers. IJCSET 2012;2(5):1231-3. 